\title{
UMA LEITURA MARXISTA DA VINCULAÇÃO HISTÓRICA ENTRE EDUCAÇÃO E CIDADANIA NO BRASIL
}

\author{
Roberto Carlos Simões Galvão_(1)
}

Resumo: Análise crítica dos posicionamentos teóricos relativos à vinculação entre educação e cidadania no Brasil. A tese do despreparo das camadas populares para a cidadania sempre fora uma constante na história política do país. Não se fará plena a cidadania de um povo sem que sejam alteradas as condições materiais geradoras da extrema desigualdade econômica nacional. A cidadania não se constrói a partir de programas educacionais, mas sim na prática social e política das classes.

A partir do momento em que nos propomos a fazer uma leitura marxista da vinculação histórica entre educação e cidadania, há que se levar em conta a atualidade de Marx. Faz sentido buscarmos compreender problemas educacionais contemporâneos partindo de pressupostos firmados no século XIX? Após a queda do Muro de Berlim (1989) e com a extinção da União das Repúblicas Socialistas Soviéticas (1991), não seria Marx um pensador ultrapassado?

Em verdade não há que se falar em autor ou em pensamento filosófico ultrapassado. Muitos dos problemas sociais e econômicos estudados por Karl Marx continuam presentes ainda hoje. O Capitalismo prossegue impondo seus preceitos e fazendo valer sua lógica social. De tal sorte, Marx passa a ser o referencial mais indicado quando se trata de discutir o momento presente.

No prefácio à edição brasileira de "Marx e a Pedagogia Moderna", do italiano Mario Manacorda, Saviani (1991, p.X) assim se expressa:

Uma filosofia é viva enquanto expressa a problemática própria da época que a suscitou e é insuperável enquanto o momento histórico de que é expressão não tiver sido superado. Ora, os problemas postos pelo marxismo são os problemas fundamentais da sociedade capitalista e enquanto estes problemas não forem resolvidos / superados não se pode falar que o marxismo terá sido superado.

O pensador marxista István Mészáros destacou-se como um dos conferencistas no Fórum Mundial da Educação, realizado em Porto Alegre, no ano de 2004. Na ocasião Mészáros (apud MENA, 2004, p.C2) concedeu uma entrevista ao jornal Folha de S. Paulo, tendo sido indagado sobre a atualidade de Marx quando se pensa a educação. O filósofo húngaro assim respondeu:

Claro que Marx continua atual. Um dos princípios marxistas que permanece absolutamente válido ainda hoje diz que os educadores não estão acima das outras pessoas. Para Marx, os educadores também devem ser educados por serem parte 
de uma sociedade que sofre mudanças constantemente. Se não se educam os educadores de maneira contínua, eles se tornam inúteis. Essa contribuição de Marx é tão válida hoje como foi no passado, como também será no futuro. É uma regra, um princípio geral.

Bottomore (2001) leciona que "os elementos de uma concepção marxista da educação começam a surgir da década de 1840, em muitas obras de Marx e Engels". Está claro, entretanto, que Marx muito pouco escreveu sobre educação, de forma direta. Porém, pode-se dizer que o conjunto de sua obra possui um caráter eminentemente educativo, no sentido de contribuir para a formação da consciência humana.

Mario Manacorda (1991, p.75) assegura que,

A teoria marxista pressupõe uma práxis educativa que, ligando-se ao desenvolvimento real da sociedade, realize a não-separação dos homens em esferas alheias, estranhas umas às outras e contrastantes, ou seja, uma práxis educativa que se funde sobre um modo de ser que seja o mais possível associativo e coletivo no seu interior $e$, ao mesmo tempo, unido à sociedade real que o circunda.

\section{CIDADANIA E PARTICIPAÇÃO POLÍTICA}

Na história do Brasil republicano, a ditadura do Estado Novo (1937-1945) e a ditadura militar (1964-1985) mantiveram o povo brasileiro afastado do processo político nacional. O Estado autoritário impôs-se como o único responsável pela nação, sendo que aos cidadãos cabia o dever de obedecer.

No período ditatorial, sobretudo entre os anos de 1964 e 1985, a educação foi marcada pela repressão, pelo tecnicismo pedagógico, pela privatização do ensino, nesse momento a cidadania foi pouco exercida.

O corolário desta experiência de autoritarismo fez com que muitas gerações se formassem sem ter desenvolvido uma consciência de cidadania e participação nas questões políticas e sociais. Um dos legados da ditadura militar foi a despolitização da sociedade, em especial da juventude. O discurso de que a política é algo ruim ainda hoje encontra forte eco na sociedade.

A socióloga Eva Maria Lakatos (1999) ao conceituar democracia deixa claro a importância da participação popular no poder:

Democracia é a filosofia ou sistema social que sustenta que o indivíduo, apenas pela sua qualidade de pessoa humana, e sem consideração às qualidades, posição, status, raça, religião, ideologia, ou patrimônio, deve participar dos assuntos da comunidade e exercer nela a direção que proporcionalmente lhe corresponde. 
Para o fortalecimento da democracia brasileira entende-se como imprescindível a formação de uma cultura participativa na população, ou seja, que haja um aumento da participação, da informação e do controle sobre os governantes.

A democracia substancial pode ser entendida como sendo um processo político destinado a tornar o cidadão cada vez mais apto a ter a própria opinião, a expressá-la e a fazê-la valer de uma maneira condizente com o bem comum.

Nesse contexto, cidadania confunde-se com participação política. Convém ressaltar a posição de Covre (1991, p.10): "as pessoas tendem a pensar a cidadania apenas em termos dos direitos a receber, negligenciando o fato de que elas próprias podem ser o agente da existência desses direitos".

No entender de Paulo Freire (2001) "o conceito de cidadania vem casado com o conceito de participação, de ingerência nos destinos históricos e sociais do contexto onde a gente está".

Infelizmente no Brasil a participação do povo no poder se limita a comparecer nas urnas de dois em dois anos. A cultura de participação é o primeiro passo para consolidar uma democracia capaz de garantir os direitos sociais dos cidadãos. Pedro Demo (2001) faz uso da expressão "cultura democrática" ao se referir à participação política dos cidadãos:

Cultura democrática seria a característica de um povo no seu modo de ser e de agir, enfim da sua organização social. É mais que uma ideologia, é algo que vai além nesse sentido, é por fim uma situação construída e institucionalizada como regra de vida, como valor comum, como modo de ser. Assim numa cultura democrática simplesmente não se tolera a desigualdade social gritante. Não se tolera a miséria, a pobreza extrema, os menores abandonados, a fome, a criminalidade resultante da injustiça social, etc. A cultura democrática representa a expressiva $e$ interessada participação popular natural nos processos do poder.

\section{O QUE PODEMOS ENTENDER POR CIDADANIA}

O termo "cidadania" está sendo vulgarizado. Muito se fala em cidadania nos mais diferentes sentidos e ocasiões, porém poucos homens têm acesso às condições sócio-econômicas que permitem o acesso à verdadeira cidadania.

Sob uma perspectiva jurídica, a expressão "cidadania" refere-se ao exercício dos direitos políticos garantidos na ordem constitucional. Assim, votar significa exercer a cidadania. De igual maneira, todo homem exerce a cidadania quando faz uso do direito que tem de candidatar-se para um cargo público. Cidadania representa a possibilidade dos cidadãos participarem do poder do Estado, direta (através de plebiscitos, referendos, etc.) ou indiretamente (elegendo seus representantes). A cidadania pode ainda representar o exercício dos direitos e garantias fundamentais, bem como o respeito aos deveres e obrigações previstos pela ordem jurídica. 
A cidadania vem sendo interpretada por teóricos de orientação marxista, como sendo o acesso pleno aos bens materiais e culturais produzidos por uma sociedade. Na sociedade capitalista, não há que se falar em cidadania para todos. A exclusão é inerente ao sistema capitalista. A miséria, do mesmo modo, está implícita na lógica social do capitalismo. Segundo Chauí (1985) o Brasil caracteriza-se por ser uma sociedade capitalista, autoritária e desigual, onde a cidadania simplesmente não existe. Não existe para a classe dominante, posto que ela não precisa de direitos sociais ou de cidadania porque tem privilégios. Não existe igualmente para a maioria da população, pois suas tentativas de conquistar direitos e garantir a cidadania são sempre interpretadas como problemas de polícia e tratadas com todo o rigor do aparato repressor do Estado.

\section{A IDÉIA DE UMA EDUCAÇÃO PARA A CIDADANIA}

A Constituição da República de 1988, em seu artigo 205, dispõe que a educação no Brasil visará, entre outras coisas, o preparo da pessoa para o exercício da cidadania. Do mesmo modo, a Lei 9.394 de 20 de dezembro de 1996 - Lei de Diretrizes e Bases da Educação Nacional, em seu artigo 2o, dispõe que a educação tem por finalidade, entre outras coisas, o preparo do educando para o exercício da cidadania. Segundo dispõe nosso ordenamento legal, educar é um ato que visa a convivência social e a cidadania, e ainda a tomada de consciência política. Assim, a educação escolar, além de ensinar o conhecimento científico, deve assumir a incumbência de preparar as pessoas para o exercício da cidadania.

A formação do ser humano inicia-se na família. Ali tem início um processo de humanização e libertação. É um caminho que busca fazer da criança um ser civilizado. Bem cedo a escola participa desse processo. Com o conhecimento adquirido na escola o aluno se prepara para a vida. A educação para a cidadania visa contribuir para fazer de cada pessoa um agente de transformação. Isso exige uma reflexão que possibilite compreender as raízes históricas da situação de miséria e exclusão em que vive boa parte da população. A formação política deve propor caminhos para mudar as situações de opressão.

A formação política tem no universo escolar um espaço privilegiado, muito embora outros segmentos participem desta formação como a família ou os meios de comunicação. Não haverá democracia substancial se inexistir esta responsabilidade propiciada, sobretudo, pelo ambiente escolar.

O problema da grave concentração de renda no Brasil, a corrupção que permeia os órgãos governamentais, a ingerência política e o descaso histórico do governo brasileiro para com os direitos fundamentais dos seus cidadãos são problemas que somente se encerrarão com o aprimoramento da democracia, e isto se dará por meio de uma maior participação do povo no poder. Considerando os problemas sociais como os acima mencionados, Cecília Peruzzo (1998) adverte:

Estes são apenas alguns dos indicativos da importância histórica da educação para a cidadania em sua contribuição para alterações no campo da cultura política, por meio da ampliação do espectro da participação política, não só em nível macro do 
poder político nacional, mas incrementando-a a partir do micro, da participação em nível local, das organizações populares, e contribuindo para o processo de democratização e ampliação da conquista de direitos de cidadania.

Expressões como democracia e cidadania se confundem. Uma condição essencial para a democracia está em que os governados queriam escolher seus governantes, queiram participar das questões do Estado, sintam-se cidadãos. Uma democracia consolidada se constrói com a participação interessada do povo no poder. Referindo-se a sociedade democrática o liberal Dewey (1979) leciona que,

Essa sociedade deve adotar um tipo de educação que proporcione aos indivíduos um interesse pessoal nas relações e direções sociais, e hábitos de espírito que permitem mudanças sociais sem o ocasionamento de desordens.

Luis Rigal (apud IMBERNÓM, 2000), do mesmo modo, vem se destacando como defensor da educação para a cidadania, e assim dispõe:

A escola também deve cumprir um papel relevante na formação de cidadãos, como sujeitos políticos, para uma democracia substantiva que os exige protagonistas, ativos e organizados: formar governados que possam ser governantes.

Mas como há de se firmar uma educação que promova a conscientização política de todos os cidadãos? Jacques Delors (2003) descreve sua concepção de educação para a cidadania:

Não se trata de ensinar preceitos ou códigos rígidos, acabando por cair na doutrinação. Trata-se sim, de fazer da escola um modelo de prática democrática que leve os alunos a compreender, a partir de problemas concretos, quais são os seus direitos e deveres, e como o exercício da sua liberdade é limitado pelo exercício dos direitos e da liberdade dos outros.

\section{A CRENÇA DE QUE A EDUCAÇÃO TRANSFORMA A SOCIEDADE}

Vem se destacando na mídia nacional, bem como no discurso de alguns teóricos da educação, como vimos há pouco, a afirmação de que é preciso conceder à educação uma especial atenção. Sobressai a assertiva de que a educação representa no Brasil, uma alavanca social, capaz de, por si só, alterar o quadro sócio-econômico do país. E alterá-lo para melhor. À educação atribui-se a tarefa de transformar a sociedade.

A Rede Globo de televisão chegou a veicular recentemente um slogan com a mensagem: "Educação é Tudo". De modo semelhante o "Futura" é um canal de televisão criado pela Fundação Roberto Marinho em parceria com a CNN, rede de televisão norte americana. O canal "Futura" tem uma programação voltada exclusivamente para a educação, e vem sendo patrocinado pelo Banco Bradesco, Grupo Votorantin entre outros poderosos grupos econômicos. 
A Fundação Bradesco, uma das mais antigas investidoras na área de educação, aplicou, no ano de 2003, R \$128,9 milhões em projetos educacionais. Em 2004 foram investidos $\mathrm{R} \$ 148,3$ milhões. A Fundação Bradesco mantém atualmente 40 escolas no país - pelo menos uma em cada Estado - e já atendeu cerca de 500 mil estudantes. A Coca-cola também se empenha em favor da educação no Brasil. Atende 33 escolas em 14 municípios de oito Estados brasileiros. A rede de supermercados Pão de Açúcar é outro exemplo de empresa de grande porte que tem como foco de seus projetos sociais a área educacional. São no total nove programas que atenderam em média a 3.600 crianças e adolescentes por dia.

A Fundação Itaú Social desenvolve um projeto que premia estudantes e professores com bolsas de estudo. As escolas dos vencedores recebem apoio para a criação ou ampliação de bibliotecas e computadores. O Itaú participa ainda da formação de oficinas de criação de textos em mais de 10 mil escolas do país. A Embraer também tem a educação como prioridade nos investimentos: são 14 projetos e cerca de $\mathrm{R} \$ 48$ milhões aplicados desde a criação do Instituto Embraer de Educação, isto no ano 2000.

Cláudio de Moura Castro (apud STACHUK, 2004, p.C7) que foi diretor da área de educação do Banco Mundial, nos E.E.U.U., estima que o valor investido em educação pelas médias e grandes empresas brasileiras gire em torno de $\mathrm{R} \$ 1$ bilhão. No ano de 1998 a Igreja Católica promoveu a sua Campanha da Fraternidade tendo por tema: "Educação: ação transformadora". Difundiu-se à época a idéia de que para transformar-se em uma democracia real e para ter condições de competir em um mercado externo cada vez mais sofisticado e exigente, o país necessita de pessoas adequadamente formadas como cidadãos (DONEGANA, 1998, p.32).

O secretário-geral da ONU, Kofi Annan (apud LUCAS, 1999, p.20), de igual modo parece acreditar no poder da educação. Vejamos estas suas palavras:

Educação é um direito humano com imenso poder de transformação. Sobre suas fundações estruturam-se a liberdade, a democracia e o desenvolvimento humano sustentável. Portanto, no limiar do século 21 não deve existir prioridade maior ou missão mais importante do que a educação para todos.

Em artigo publicado no jornal Folha de S. Paulo, Elio Gaspari (2005, p.D8) informa que na capital paulista um grupo de empresários procurou a Prefeitura oferecendo apoio para a melhoria da rede municipal de ensino. Os empresários pretendem trabalhar na busca de soluções para problemas administrativos e logísticos. "Certamente colocarão dinheiro no projeto", informa o jornalista.

No município de Apucarana, região norte do Paraná, sob a administração do PFL - Partido da Frente Liberal, foi adotado o slogan "cidade educação". O atual prefeito defende a idéia de que o investimento em educação há de trazer a prosperidade para uma cidade onde falta emprego, saneamento básico, habitação, atendimento médico, etc. Como Apucarana, centenas de cidades espalhadas pelo país são bombardeadas com a tese de que o investimento em educação transformará a sociedade. O governo federal corrobora esta idéia. 
Procurei acima demonstrar alguns exemplos que comprovam a ênfase atribuída à educação na contemporaneidade, no Brasil e no mundo. Tudo isso nos induz a perguntar, como fez Miguel Arroyo: "por que tanta ênfase na educação?". O que pretendem grandes grupos econômicos ao promoverem altos investimentos na área de educação no país?

Na verdade muitas das ações sociais na área educacional, praticadas por banqueiros e empresários, são utilizadas para vender uma boa imagem e aumentar os lucros, ou seja, é uma excelente estratégia de marketing. A riqueza dos bancos (REVISTA BANCÁRIOS, 2005, p.15), em especial, teve um crescimento de 51,23 \% entre 1999 e 2002, o que comparado a outros setores da economia é muito alto. Ainda assim, os investimentos dos bancos voltados para educação são muito poucos e insignificantes, se comparados aos lucros do setor, que nos últimos 10 anos superou $1000 \%$.

Arrisco dizer que a caridade dos grandes capitalistas em relação à educação no Brasil tem uma explicação. Nesse sentido, valho-me dos dizeres do filósofo John Dewey (1980, p.311):

A caridade pode, mesmo, ser usada como meio de administrar um calmante à própria consciência social, ao mesmo tempo que elimina o ressentimento que, de outro modo, poderia desenvolver-se naqueles que sofrem com a injustiça social. A filantropia magnânima poderá ser empregada para encobrir brutal exploração econômica. Doações a bibliotecas, hospitais, missões e escolas poderão ser empregadas como meio de tornar mais toleráveis as instituições existentes, e de criar imunidades contra mudanças sociais.

Conforme veremos, a vinculação entre educação e cidadania tem uma representação histórica no Brasil. É claro que a educação não tem o poder de transformar ou alavancar uma sociedade. As causas da má distribuição de renda, da miséria e da subnutrição no Brasil, estão muito além do alcance de iniciativas pontuais no âmbito da educação. É necessário, portanto, desfazer a concepção equivocada em torno de uma solução simplista e reducionista em torno da educação, que acaba sendo apresentada como panacéia para todos os problemas sem considerar a complexidade que a envolve.

\section{A ESCOLA REPRODUZ A SOCIEDADE QUE AÍ ESTÁ}

É inegável que as condições sociais e políticas necessárias ao exercício da cidadania ainda não existem no Brasil. O país está em processo de democratização, posto não haver democracia política separada da democracia econômica -, e nesse contexto, a educação, como vimos, vem sendo apontada como fator imprescindível à conquista da cidadania. O mestre Arroyo (2003) leciona que "reduzir a questão da cidadania dos trabalhadores a uma questão educativa é uma forma de ocultar a questão de base. É o que se tenta fazer quando se põe a educação como precondição para a cidadania". Aquilo que Arroyo denomina questão de base diz respeito às condições materiais necessárias à consolidação da cidadania. Isto veremos. 
A exclusão social, a miséria $e$ a desigualdade econômica são apontadas como problemas passíveis de serem solucionados por intermédio da educação. Esta disporia de autonomia em relação à sociedade, estando capacitada a intervir no sentido de transformar a realidade econômica e promover a justiça social. Será isto possivel? É possível abstrair a resposta para esta questão a partir de uma passagem de Marx (1986, p.72), vejamos:

As idéias da classe dominante são, em cada época, as idéias dominantes; isto é, a classe que é a força material dominante da sociedade é, ao mesmo tempo, sua força espiritual dominante. A classe que tem à sua disposição os meios de produção material dispõe, ao mesmo tempo, dos meios de produção material espiritual, o que faz com que a ela sejam submetidas, ao mesmo tempo e em média, as idéias daqueles aos quais faltam os meios de produção espiritual.

Na escola, ou em qualquer ambiente que se pretenda educativo, as idéias dominantes serão aquelas que favoreçam ou atendam os interesses capitalistas. Estando a escola inserida em um contexto sócio-econômico definido, ou seja, fazendo ela parte de uma sociedade capitalista, de classes, onde dominantes exploram dominados, há que se supor que a educação ali promovida acaba por refletir o ideal político dominante naquela sociedade.

Jean-Claude Passeron e Pierre Bourdieu foram dois renomados sociólogos da educação em França. Ambos desenvolveram a chamada Teoria da Reprodução, segundo a qual a escola reproduz a sociedade de classes e reforça o modo de produção capitalista. A função da educação seria a de reprodução das desigualdades sociais. Pela reprodução cultural a escola contribui especificamente para a reprodução social. A partir do pensamento de Bourdieu e Passeron muitos outros teóricos da educação desenvolveram suas idéias que caminham em sentido semelhante. Paulo Ghiraldelli (2000) assim dispõe:

As teorias crítico-reprodutivistas, de maneira sistemática e organizada, forneceram à intelectualidade um instrumental capaz de desmistificar a idéia de que a educação (ou a escola) teria um poder de intervenção nas tramas sociais capaz de corrigir as injustiças e obter equalização social. (...) Os críticos-reprodutivistas, grosso modo e em que pese suas diferenças, concluíram que à escola formal restava o papel de reprodutora da sociedade de classes, reforçadora do modo de produção capitalista $e$, por isso mesmo, repressora, autoritária e inculcadora da ideologia dominante.

É claro que sendo um instrumento de reprodução das relações de produção, a escola em uma sociedade capitalista como a do Brasil, necessariamente há de reproduzir a exploração econômica. A escola não tem uma autonomia como pensam, ingenuamente alguns intelectuais. Vejamos a lição do mestre Saviani (1985, p.34):

Enquanto as teorias não-críticas pretendem ingenuamente resolver o problema da marginalidade, através da escola sem jamais conseguir êxito, as teorias crítico- 
reprodutivistas explicam a razão do suposto fracasso. O aparente fracasso é na verdade o êxito da escola.

Como se percebe, a educação, longe de ser um fator de superação dos problemas sócio-econômicos da nação, constitui um elemento reforçador dos mesmos.

Transformando os alunos em reprodutores do sistema econômico dominante, a escola acentua o espírito de competição entre os indivíduos e faz com que os mais fortes ocupem os espaços disponíveis e os mais fracos sejam impiedosamente eliminados. A educação, diante do exposto, não passa de um processo pelo qual a sociedade, por intermédio da escola, transmite seus conhecimentos, seus valores, sua cultura de uma geração para outra. Lembrando, pois, que os valores, conhecimentos e cultura dominantes na educação de uma dada época, serão os valores, conhecimentos e cultura da classe dominante de então. Lopes (apud PIMENTA, 1999, p.67) expõe de forma magistral o lugar da educação na sociedade:

Vê-se que a educação é parte do contexto social, do tempo, dos valores, das condições materiais e dos acontecimentos históricos em que se encontra e aos quais se integra. As relações internas e externas à instituição educacional dependem e se determinam pela vida dos homens, aos quais a ação educativa se destina. As aspirações destes, suas contradições seus impasses, seus valores, suas visões de mundo e, fundamentalmente, o seu modo de produção material sustentam e dão significado à instituição educacional.

\section{O LUGAR DA EDUCAÇÃO NA SOCIEDADE}

A educação não resolve o problema da desigualdade social, da miséria, da exclusão e tantos outros. A educação reproduz a sociedade de classes, reproduz a exclusão social. Nem por isso poderá este setor de interesse público desmerecer os investimentos do Estado. Educação é fundamental, mas não é tudo. Educação não é mais importante que moradia, saneamento básico, saúde, salário digno e acesso pleno a todos aqueles benefícios produzidos por uma sociedade. Paulo Freire (2001, p.102) leciona que,

Não devemos nem aceitar o todo-poderosismo ingênuo de uma educação que faz tudo, nem aceitar a negação da educação como algo que nada faz, mas assumir a educação nas suas limitações e, portanto, fazer o que é possível, historicamente, ser feito com e através, também, da educação.

E complementa o emérito autor (IBIDEM, p.175):

Quando a gente reflete sobre os limites da educação e a possibilidades da educação, é preciso ter cuidado para não exagerar na positividade e não exagerar na negatividade, ou em outras palavras, não exagerar na impossibilidade e não exagerar na possibilidade. Quer dizer, a educação não pode tudo, mas a educação pode alguma coisa e deveria ser pensada com grande seriedade pela sociedade. 
Segundo Manacorda (1991, p.96) é possível também a partir da leitura de Marx, estabelecer uma advertência no seguinte sentido:

Não se confiar demais nas possibilidades revolucionárias de um sistema escolar frente à sociedade, da qual é produto e parte, mas, ao mesmo tempo, também de se eliminar todo adiamento pessimista e omisso de intervir neste setor somente após a revolução, isto é, quando as estruturas sociais já tenham sido modificadas.

Por que então tem havido tanta ênfase na educação, como pudemos demonstrar? Bancos e grupos empresariais poderosos investem em educação sugerindo que tendo acesso à educação, o cidadão resgatará sua cidadania. Ou seja, desde que freqüente a escola o indivíduo passa a ter a possibilidade de transformar-se e de transformar o mundo em que vive. Mas isto não é real. A consciência do cidadão não dispõe de poder para alterar o quadro social no qual está inserido. As condições de existência determinam a consciência, e não o contrário. Conforme podemos ler em Marx (1986, p.37),

(...) mas os homens, ao desenvolverem sua produção material e seu intercâmbio material, transformam também, com esta sua realidade, seu pensar e os produtos de seu pensar. Não é a consciência que determina a vida, mas a vida que determina a consciência.

No Prefácio de sua obra "Para a Crítica da Economia política" Marx (1982, p.25) reafirma,

O modo de produção da vida material condiciona o processo em geral de vida social, política e espiritual. Não é a consciência dos homens que determina o seu ser, mas, ao contrário, é o seu ser social que determina sua consciência.

Em resumo, não será a partir de uma política que valorize a educação que a sociedade se tornará justa. A cidadania se dá a partir do investimento nas condições materiais de vida dos homens. Porém, pôr fim à miséria dos despossuídos - o que significa alterar aspectos materiais da sociedade -, compromete interesses e privilégios dos poderosos. Logo, defende-se o investimento em educação.

Cada homem, tendo tido acesso à educação escolar, há de por si só, como crêem os liberais, ascender socialmente. Se não o fizer, terá sido por sua exclusiva culpa. A ele foram dadas as condições para a conquista da cidadania, alega-se. Trata-se é claro, de um engodo. O grande mérito de Marx foi ter demonstrado que a desigualdade social, a miséria e a exclusão econômica são fatores em nada relacionados com o grau de cultura dos homens, ou com o número de anos passados na escola. Em verdade, tudo depende fundamentalmente do tipo de relação que os indivíduos têm com os meios de produção.

Sabiamente, Arroyo (2003, p.75) questiona: 
É fundamental captar se a cidadania se constrói através de intervenções externas, de programas e agentes que outorgam e preparam para o exercício da cidadania, ou, ao contrário, a cidadania se constrói como um processo que se dá no interior da prática social das classes.

Os reais determinantes sociais e econômicos da exclusão da cidadania precisam ser evidenciados para que então se possa alterar a educação, alterando sua base material. Não será preciso tornar-se culto para exercer o direito natural a não morrer de fome.

\section{CONSIDERAÇÕES FINAIS}

Vimos que a educação por si só, não pode garantir oportunidades de ascensão social se a economia não as gera. As bases econômicas e materiais da sociedade capitalista irão determinar a divisão de classes, a desigualdade e a própria educação. Coube-nos, neste breve artigo, a tarefa de esclarecer a relação histórica entre educação e cidadania no Brasil. Buscamos, nesse sentido, demonstrar que a educação tem lá sua importância, todavia, não possui o alegado poder de transformação da sociedade.

Na verdade a ênfase na educação para as massas vem desde Adam Smith (1983, p.217). O economista político defendia a educação como necessária à manutenção da ordem social que estava posta.Vejamos:

Quanto mais instruído for o povo, tanto menos estará sujeito às ilusões do entusiasmo e da superstição que, entre nações ignorantes, muitas vezes dão origem às mais temíveis desordens. Além disso, um povo instruído e inteligente sempre é mais decente e ordeiro do que um povo ignorante e obtuso.

A educação exigida como requisito à cidadania representa a negação da racionalidade própria da classe trabalhadora. A elite dominante quer impor seu ideal de educação. Trata-se de uma formação sem a qual o homem não teria direito aos bens produzidos pela sociedade. É o alegado. Em verdade, a classe trabalhadora já possui o direito à igualdade de acesso aos bens materiais e culturais que aí estão. Assim, a educação representa não o meio de acesso aos referidos bens, mas, pelo contrário, o entrave que justifica e racionaliza sua exclusão.

\section{Referências}

ARROYO, Miguel et ali. Educação e cidadania: quem educa o cidadão, São Paulo: Cortez, 2003.

BOTTOMORE, Tom. Dicionário do pensamento marxista, Rio de Janeiro: Zahar, 2001.

CHAUÍ, Marilena. Primeira filosofia, São Paulo: Brasiliense, 1985. 
COVRE, Maria de Lourdes Manzini. O que é cidadania, São Paulo: Brasiliense, 1991.

DELORS, Jacques. Educação: um tesouro a descobrir, 8o ed., São Paulo: Cortez; Brasília, DF: MEC: UNESCO, 2003.

DEWEY, John. Teoria da vida moral, São Paulo: Abril Cultural, 1980, p.311

Democracia e educação: introdução à filosofia da educação, 4.ed., São Paulo: Nacional, 1979.

DONEGANA, Constanzo. Educação: ação transformadora, São Paulo: Revista Cidade Nova, fev/1998.

FREIRE, Paulo; FREIRE, Ana Maria Araújo (org.). Pedagogia dos sonhos possíveis, São Paulo: Ed. UNESP, 2001.

GASPARI, Elio. Empresários nas escolas, São Paulo: Folha de S. Paulo, 06/02/ 2005, p. D8.

GHIRALDELLI JR., Paulo. História da educação, São Paulo: Cortez, 2000.

IMBERNÓN, Francisco (org.). A educação no século XXI: os desafios do futuro imediato, 2.ed., Porto Alegre: Artes Médicas, 2000.

LAKATOS, Eva Maria. Sociologia Geral, 7a ed. São Paulo: Atlas, 1999.

LUCAS, Jaime. Escola: crise e desafios, São Paulo: Revista Cidade Nova, jun/1999.

MANACORDA, Mario Alighiero. Marx e a pedagogia moderna, Prefácio de Dermeval Saviani, São Paulo: Cortez : Autores Associados, 1991.

MARX, Karl. O capital, in Os Pensadores, Vol.1, São Paulo: Abril Cultural, 1983.

Abril Cultural, 1982.

Para a crítica da economia política, in Os Pensadores, São Paulo: ; ENGELS, F. A ideologia alemã, 5.ed., São Paulo: Hucitec, 1986.

MENA, Fernanda. Escola não expande valores humanos, São Paulo: Folha de S. Paulo, 01/08/2004, p.C2.

PIMENTA, Selma Garrido. Saberes pedagógicos e atividade docente, São Paulo: Cortez, 1999.

REVISTA BANCÁRIOS. A responsabilidade social dos bancos é bastante limitada, 2.ed., Curitiba: Federação dos Bancários da CUT, 2005. p. 15. 
SAVIANI, Dermeval. Escola e democracia, São Paulo: Cortez, 1985.

SMITH, Adam. A riqueza das nações: investigação sobre sua natureza e suas causas, Vol. II, São Paulo: Abril Cultural, 1983.

STACHUK, Mayra. 11\% das empresas investem em educação, São Paulo: Folha de S. Paulo, 19/12/2004, p.C7.

(1) Mestrando em Educação pela Universidade Estadual de Maringá. Bolsista da CAPES.rcsgalvao@bol.com.br 